\title{
International Pesticide Operator Safety Meeting 2021: hand-held application scenarios in low- and middle-income countries
}

\author{
Markus Röver ${ }^{1}\left[\right.$ ] Anugrah Shaw ${ }^{2} \cdot$ Christian J. Kuster $^{3}$
}

Published online: 6 January 2022

(c) The Author(s) 2022

\begin{abstract}
An international web meeting on the topic of operator safety for pesticide operators was held on 20-21 September 2021. The meeting provided an opportunity for experts from regulatory agencies, pesticide industry, the Food and Agriculture Organization (FAO), and other organizations to discuss operator safety in low- and middle-income countries (LMIC). The meeting focused on risk assessment and risk mitigation, the first steps to address operator safety. The key message at the meeting was the need for an operator exposure model that includes common hand-held scenarios used in LMIC and consistent personal protective equipment communication. The experts supported a transparent collaborative process that will enable us to build on the past efforts.
\end{abstract}

\section{Introduction}

Operator exposure to plant protection products (PPP) has been a topic of discussion for several decades. In late 1980's and early 1990's, parallel operator exposure databases were developed in the United States and several European countries, which resulted in initial operator exposure models used in a regulatory context [German model, UK-POEM, Pesticide Handler Exposure Database (PHED), and Dutch Model]. Based on these initial models, the estimated exposures could be compared with the applicable limit values. This is the basis for an exposure-based or risk-based prescription or recommendation of personal protective equipment (PPE).

Further operator exposure studies have been conducted over the years, primarily in the United States and European Countries. Along with a more sophisticated statistical analysis, the new data resulted in more realistic exposure models [Agriculture Operator Exposure Model (AOEM) and US EPA Surrogate Table]. In particular, mechanized spraying

Markus Röver

markus.roever@bvl.bund.de

1 Federal Office of Consumer Protection and Food Safety (BVL), Braunschweig, Germany

2 University of Maryland Eastern Shore, Princess Anne, MD 21853, USA

3 Bayer AG Crop Science Division, Monheim am Rhein, Germany scenarios, such as pesticide application using a tractor mounted boom sprayer for arable crops or airblast sprayers for orchards and vineyards, are well represented in the operator exposure models that are currently used in a regulatory context. However, those models only contain limited data for hand-held operator exposure scenarios commonly used in most regions of the world. Besides a limited set of appropriate hand-held exposure studies, the sheer diversity and connected exposure variability of different hand-held scenarios makes it even more difficult to develop an accurate exposure estimate for those equipment scenarios. However, because a PPP application using hand-held devices is still the most common operator exposure scenario in many regions in Asia, Africa and Latin America, the improvement in exposure modelling for those scenarios is urgently needed to improve operator safety assessment.

The need for development of a global database of (handheld) exposure data and a model that focuses in particular on hand-held application scenarios was identified as a major recommendation of a 2-day virtual meeting.

- The meeting was organized by the International Center for PPE for Pesticide Operators and Re-entry Workers (ICPPE), University of Maryland Eastern Shore. ICPPE is an independent entity with extensive experience in protective clothing. Several international collaborative initiatives to improve operator and worker safety using a risk-based approach for PPE requirements have been coordinated by ICPPE. 
- The Steering Committee consisted of Beatrice Grenier (FAO Observer), Sabine Martin [German Federal Institute for Risk Assessment (BfR) —regulatory risk assessor], Christian J. Kuster (Bayer AG-industry risk assessor), Markus Röver [Federal Office ofConsumer Protection and Food Safety (BVL) - regulatory risk manager], Jurgen Schwarz (University of Maryland Eastern Shore, Associate Dean for Research), and Anugrah Shaw ${ }^{1}$ (Project Coordinator, ICPPE).

- The meeting was attended by regulators (from Australia, Belgium, Brazil, Germany, Greece, Spain, Switzerland, and United States), pesticide industry experts, FAO observers, and PPE experts. A relatively small forum with 18 experts provided an opportunity for active discussion on current global situation in general and applicability to LMIC in particular.

\section{Meeting content}

The Opening Session included a short presentation by the FAO observer on the FAO Pesticide Registration Toolkit, which includes guidance and options for regulators in LMIC to assess operator exposure and associated risks. In terms of operator safety, the FAO Toolkit ${ }^{2}$ currently references two operator exposure models:

- The CropLife OPEX Tool is an operator exposure model developed by the industrial association CropLife international (CLI). It is based on normalized metric exposure measurement units that were mainly taken from the US-EPA Occupational Pesticide Handler Unit Exposure Surrogate Reference Tables, for almost all application scenarios. For a backpack sprayer applying powder-based formulations it is supplemented by exposure data from the German Model. The CLI model is acknowledged for its simplicity and was based on available data at the time of its publication ( 2013).

- $A O E M$ is a model that is based on European industry exposure studies and was developed in a joint collaboration project led by the BfR with the participation of European Member States regulatory authorities, and PPP industry. It is known for the thorough statistical analysis and the modular assembly that allows different PPE assumptions. The AOEM project is an excellent example of a transparent and comprehensive collaboration process. Since 2014, the AOEM is part of the EFSA guid-

\footnotetext{
${ }^{1}$ For additional information or interest in joining the initiative, please contact Anugrah Shaw at ashaw[at]umes.edu.

2 FAO Pesticide Registration Toolkit Brochure, http://www.fao.org/ pesticide-registration-toolkit/en/. Accessed 15 November 2021.
}

ance on non-dietary pesticide exposure and routinely requested for the registration of plant protection products in the EU (EFSA 2014).

Even though both models, the CLI OPEX Tool and the AOEM, are milestones in the assessment of operator exposure, applicability to hand-held application scenarios is needed. As stated in the FAO presentation at the meeting, "FAO recognizes that current models may not include sufficient exposure data for pesticide application scenarios most relevant to LMICs (e.g., hand-held applications). FAO welcomes the generation of such data and associated models/ scenarios relevant to LMICs."

At the meeting, FAO clarified that for future consideration in the FAO Toolkit, a new or amended operator exposure model must meet the following criteria:

- In principle, existing and validated regulatory (risk) assessment methods are included that have been developed and/or used by independent international or national entities.

- Proposed methods/models or information are not "endorsed" by FAO.

- Methods and information that can be seen to be biased, or where a conflict of interest might be raised, will not be included in the Toolkit—even if quality is uncontested.

- FAO does not itself review scientific data with the specific aim to include that in the Toolkit, nor does it develop its own risk assessment models. It relies on independent expertise to review the raw data and model for possible reference in the FAO Toolkit.

Collaboration among stakeholders on eye-level with a transparent process during exposure data compilation, data evaluation and model development was proposed at the meeting, similar to that used for the development of the outdoor AOEM model led by BfR (Großkopf et al. 2013). Technical Working Groups would drive the discussion.

The following guiding principles for successful outcomes were shared at the meeting:

- Build on the past accomplishments and international expertise.

- Apply sound science as a guiding principle.

- Establish working groups of technical experts representing stakeholders from industry and regulatory bodies as well as neutral entities as stakeholders or observers.

- Promote open candid technical discussions (including on topics with opposing views) and seek for compromises.

- Work collectively to obtain and share information/data/ resources.

- Promote transparency by broadly circulating documents for comments and through publications. 
- Acknowledge the perceived or real potential for conflicts of interest.

Based on the comments by FAO, there was a need to identify an independent entity (e.g., a university or research institute, or a reputable regulatory body) to host/maintain the global database/model. Based on the experience gained during the AOEM development process, a BVL/BfR partnership was proposed in order to support hosting the global database and leading the discussion:

- As the lead agency for the AOEM, the BfR has the expertise and experience required for the database/model to be developed. The AOEM serves as an example of a collaborative model with a very transparent process. The process and data have been published on the BfR website as well as in a peer reviewed journal (Großkopf et al. 2013).

- The BVL works closely with BfR on risk assessment and interacts with other stakeholders on risk mitigation. BVL has developed a national guidance document and a database of PPE products to assist in PPE selection.

The technical discussion at the meeting focused on a. Development of a Global Database; b. Dermal Absorption of Pesticides via Skin Contact; c. PPE for Operator Safety; and d. Simplified Risk Assessment Approaches. Experts actively participated in technical discussions and agreed to serve in one or more of the Working Groups for future discussions. The initial discussion will focus on global database development and on PPE for operator safety. Dermal absorption and simplified risk assessment topics are scheduled for discussion after the development of the global database.

\section{Meeting conclusions}

The following major challenges need to be addressed prior to development of a global database:

- Availability of sufficient hand-held exposure data that can be accessed and used to develop a new model or to improve an existing one. The working group relies on the willingness of different stakeholders from industry and governmental institutions to share their data without compensation.

- Resources for development and maintenance of a global database, statistical analysis for model elaboration, and project coordination.

- Involvement of regulators from LMIC, as it is important for (potential) users of the FAO toolkit to be actively engaged in the future risk assessment model.
This project is in its initial stages of development, building on the discussions and acceptance by experts to actively participate in the respective working groups. Individuals with diverse technical and/or administrative expertise have agreed to serve on the Steering Committee.

Several experts who attended the meeting also expressed an interest in the partnership approach to improve operator and worker safety in Europe. A separate virtual meeting was scheduled for November 2021 to focus on expanding the PPE partnerships in Europe. At the meeting, the following initiatives will be presented:

- The German PPE requirements guideline and the PPE database.

- The French initiative on operator safety that spans from risk assessment to consistent safety communication by stakeholders to the farmers.

- The Swiss tool-kit for operator protection based on sets of standard PPE combined with a color code.

The meeting in November 2021 will also include discussions on PPE equivalencies and on the use of international standards for PPE to effectively communicate PPE requirements for risk mitigation. This topic overlaps with globally held discussions, which includes the use of partial body garments for additional protection. Constraints such as cost, comfort, availability is important part of PPE discussion.

Funding Open Access funding enabled and organized by Projekt DEAL.

\section{Declarations}

Conflict of interest Christian J. Kuster is an employee of the agrochemical company Bayer AG. The meeting took place under the auspices of the ICPPE. The activities of the ICPPE aim to bring together stakeholders from all sectors to develop broadly acceptable solutions. None of the authors have a conflict of interest.

Open Access This article is licensed under a Creative Commons Attribution 4.0 International License, which permits use, sharing, adaptation, distribution and reproduction in any medium or format, as long as you give appropriate credit to the original author(s) and the source, provide a link to the Creative Commons licence, and indicate if changes were made. The images or other third party material in this article are included in the article's Creative Commons licence, unless indicated otherwise in a credit line to the material. If material is not included in the article's Creative Commons licence and your intended use is not permitted by statutory regulation or exceeds the permitted use, you will need to obtain permission directly from the copyright holder. To view a copy of this licence, visit http://creativecommons.org/licenses/by/4.0/. 


\section{References}

EFSA (2014) Guidance on the assessment of exposure of operators, workers, residents, and bystanders in risk assessment for plant protection products. EFSA J 12(10):3874. https://doi.org/10.2903/j. efsa.2014.3874

Großkopf C, Mielke H, Westphal D, Erdtmann-Vourliotis M, Hamey P, Bouneb F, Rautmann R, Stauber F, Wicke H, Maasfeld W, Salazar JD, Chester G, Martin S (2013) A new model for the prediction of agricultural operator exposure during professional application of plant protection products in outdoor crops. J Verbr Lebensm 8:143-153. https://doi.org/10.1007/s00003-013-0836-x

Publisher's Note Springer Nature remains neutral with regard to jurisdictional claims in published maps and institutional affiliations. 